\title{
Effects of Equivalence Ratio on Species and Soot Concentrations in Premixed N-Heptane Flames
}

\author{
FIKRET INAL* \\ Department of Chemical Engineering, Izmir Institute of Technology, Gulbahce Koyu, 35437 Urla-Izmir, Turkey \\ and \\ SELIM M. SENKAN \\ Department of Chemical Engineering, University of California Los Angeles, Los Angeles, CA 90095, USA
}

\begin{abstract}
The micro-structure of laminar premixed, atmospheric-pressure, fuel-rich flames of n-heptane/oxygen/argon has been studied at two equivalence ratios $(\mathrm{C} / \mathrm{O}=0.63$ and $\mathrm{C} / \mathrm{O}=0.67)$. A heated quartz microprobe coupled to an online gas chromatography/mass spectrometry (HP 5890 Series II/HP 5972) has been used to establish the identities and absolute concentrations of stable major, minor, and trace species by the direct analysis of samples withdrawn from the flames. Benzene was the most abundant aromatic compound identified. The largest PAH detected were the family of $\mathrm{C}_{18} \mathrm{H}_{10}$ (molecular weight of 226) that include cyclopenta[cd]pyrene and benzo[ghi]fluoranthene, with peak concentrations reaching $8 \mathrm{ppm}$ and $6 \mathrm{ppm}$, respectively. Soot particle diameters, number densities, and volume fractions were determined using classical light scattering and extinction measurements. The largest soot particle diameter measured was about $18 \mathrm{~nm}$ and the soot volume fraction reached the amount of $4.9 \times 10^{-7}$. (C) 2002 by The Combustion Institute
\end{abstract}

\section{INTRODUCTION}

Combustion of fossil fuels is one of the major sources of air pollution in many areas. Heptane is a component of commercial gasoline and one of the primary reference fuels for the determination of gasoline octane number. The oxidation of n-heptane has been investigated in shock tubes $[1,2]$, jet-stirred reactors $[3,4]$, premixed [5-7], and diffusion [8,9] flames.

Coats and Williams [10] studied the ignition of n-heptane/oxygen/Ar mixtures behind incident and reflected shock waves for equivalence ratio $(\phi)$ of 0.5 to 4.0 in the temperature range 1300 to $2000 \mathrm{~K}$. They monitored the chemiluminescence emission from $\mathrm{OH}, \mathrm{CH}$, and $\mathrm{C}_{2}$ with infrared emission from $\mathrm{CO}, \mathrm{CO}_{2}$, or species containing bonded $\mathrm{C}-\mathrm{H}$ and also soot emission. Interestingly, higher soot emission signals were observed for $\phi=2.0$ than for $\phi=4.0$. Trace deposits of condensed material or soot with typical particle diameters less than $20 \mathrm{~nm}$ were also found on the tube walls.

$\mathrm{PAH}$ and soot formation in premixed flames of toluene, toluene/n-heptane, and n-heptane were investigated by Westmoreland et al. [5]. The entire stream of combustion products was

*Corresponding author. E-mail: inal@likya.iyte.edu.tr. collected by a glass hood and flame samples were taken using glass filter and XAD-2 polymeric resin. They studied a heptane flame at equivalence ratio of 2.05. However, neither the $\mathrm{PAH}$ profiles as a function of distance from the burner nor the major species concentrations were reported for the heptane flame in this study. In all flames, the most abundant compound was acenaphthylene.

Concentration profiles of stable species $\left(\mathrm{C}_{7} \mathrm{H}_{16}, \mathrm{O}_{2}, \mathrm{~N}_{2}, \mathrm{C}_{2} \mathrm{H}_{4}, \mathrm{H}_{2}, \mathrm{H}_{2} \mathrm{O}, \mathrm{CO}_{2}, \mathrm{CO}, \mathrm{CH}_{4}\right.$, $\mathrm{C}_{2} \mathrm{H}_{2}, \mathrm{C}_{3} \mathrm{H}_{6}, \mathrm{C}_{2} \mathrm{H}_{6}$ ) were obtained by Hamins and Seshadri [8] in counterflow diffusion flames burning heptane, toluene, binary solutions of methanol and toluene, and heptane and toluene, and ternary solutions of methanol, heptane, and toluene with quartz microprobe sampling and gas chromatography analysis.

Semiquantitative concentration profiles of the most abundant fluorescing PAH have been estimated in laminar diffusion flames of nheptane by Petarca and Marconi [9]. Species reported in this study were naphthalene, acenaphthylene, phenanthrene, anthracene, pyrene, fluoranthene, perylene, 3,4-benzopyrene, anthanthrene, coronene, and 1,12-benzoperylene. Acenaphthylene and naphthalene were the compounds with the highest concentrations, which agrees with earlier premixed 


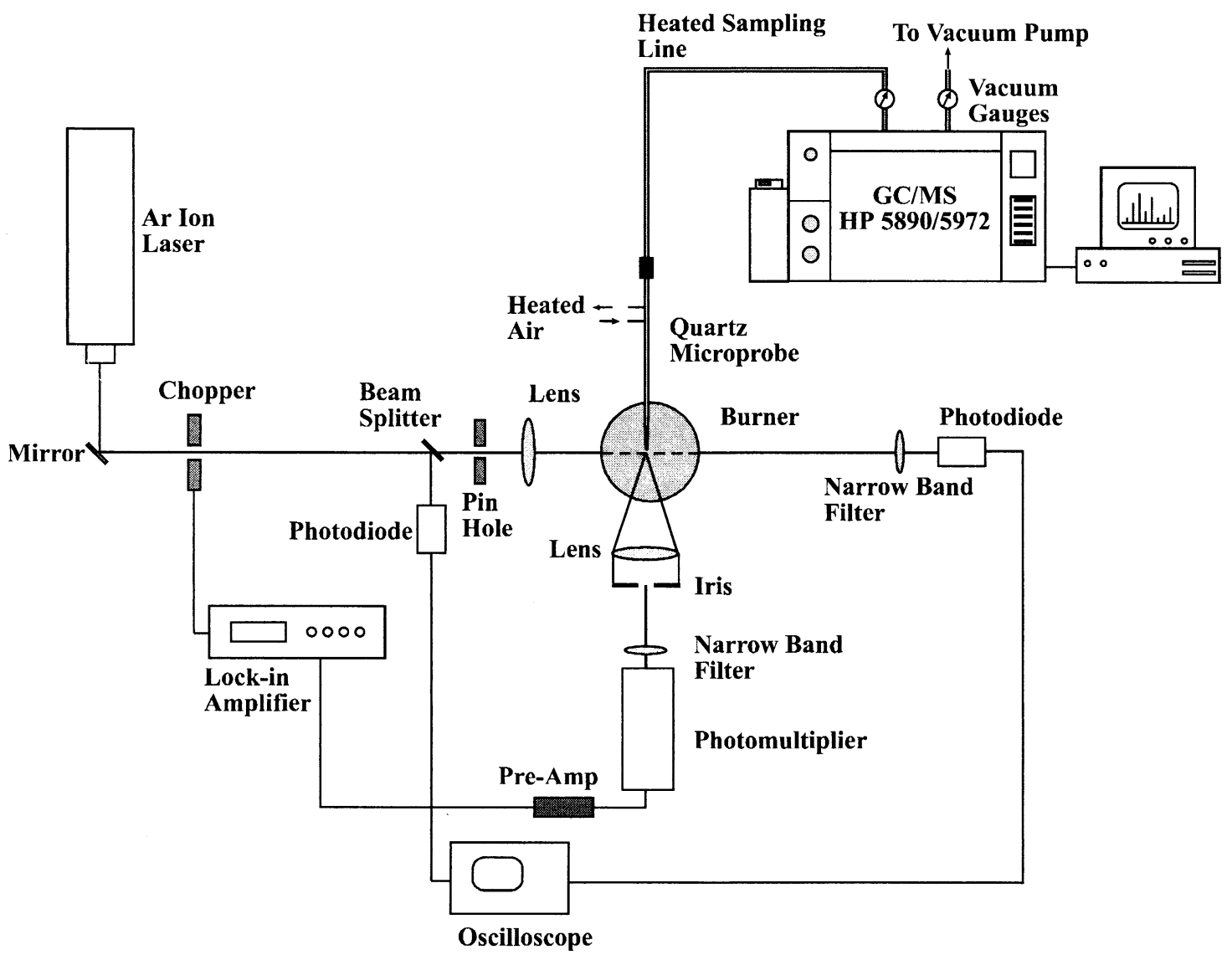

Fig. 1. Experimental setup.

flame results of Westmoreland et al. [5]. The maximum soot volume fraction reported was $\mathrm{f}_{\mathrm{v}}=3.3 \times 10^{-7}$.

Doute et al. [6] obtained the mole fraction profiles of stable species and free radicals in low-pressure $(6.0 \mathrm{kPa})$, premixed laminar $\mathrm{n}$ heptane/oxygen/Ar flames using molecular beam mass spectrometry. Atmospheric-pressure, premixed laminar n-heptane/air flame at stoichiometric composition has recently been studied experimentally and computationally by Ingemarsson et al. [7]. They detected about 30 stable organic species using online GC/MS system.

In this study, we report major, minor, and PAH species concentration profiles with soot measurement results and their dependencies on combustion parameter equivalence ratio in well-characterized premixed, laminar, flat flames of n-heptane/oxygen/Ar at equivalence ratios of $1.97(\mathrm{C} / \mathrm{O}=0.63)$ and $2.10(\mathrm{C} / \mathrm{O}=$ $0.67)$.

\section{EXPERIMENTAL}

An illustration of the experimental system used for the determination of microstructures of premixed flames is shown in Fig. 1. Atmospheric pressure, premixed, flat flames of $\mathrm{n}-\mathrm{C}_{7} \mathrm{H}_{16}$ $\mathrm{O}_{2} /$ Ar were stabilized over a $50-\mathrm{mm}$ diameter porous, bronze burner. Ar was also used as shield gas to protect the flames from surrounding air. Oxygen (99.99\%) and argon (99\%) were supplied from Airco Welding Supply (Pomona, CA). n-Heptane (99\%) was acquired from Sigma Aldrich. The flow rates of oxygen and argon were controlled by calibrated mass flow controllers (Model 247C, MKS). The shield gas was regulated by a calibrated rotameter. The 
TABLE 1

The Pre-Combustion Compositions of the Flames Studied

\begin{tabular}{|c|c|c|}
\hline \multirow[b]{2}{*}{ Reactant } & \multicolumn{2}{|c|}{ Mole $\%$} \\
\hline & $\begin{array}{c}\text { Eqv. Ratio } 1.97 \\
\text { (Flame A) } \\
\text { (initial velocity } \\
5.25 \mathrm{~cm} / \mathrm{s} \text { ) }\end{array}$ & $\begin{array}{l}\text { Eqv. Ratio } 2.10 \\
\text { (Flame B) } \\
\text { (initial velocity } \\
5.17 \mathrm{~cm} / \mathrm{s} \text { ) }\end{array}$ \\
\hline n-Heptane & 5.33 & 5.50 \\
\hline $\mathrm{O}_{2}$ & 29.70 & 28.79 \\
\hline $\mathrm{Ar}$ & 64.97 & 65.71 \\
\hline
\end{tabular}

reactant mixture was prepared by injecting the n-heptane into the preheated mixture of oxygen and argon at $150^{\circ} \mathrm{C}$. A high-precision syringe pump (Isco Model 260D Syringe Pumps with Series D Pump Controller) was used to introduce liquid fuel into mixed argon-oxygen stream. The syringe pump had flow rate resolution of $1 \mu \mathrm{L} / \mathrm{min}$ and flow rate accuracy of $\pm 0.5 \%$. Argon shield gas was also heated to the temperature of the reactant mixture. Temperatures at different locations were monitored and kept constant by a multi-channel temperature read-out and proportional temperature controllers (Omega Engineering Inc.).

The flame samples were withdrawn with an air heated quartz microprobe at a temperature of about $300^{\circ} \mathrm{C}$ (Fig. 1). Samples were then transferred through a heated, glass-lined, stainless-steel sampling line to a GC/MS system (HP 5890 Series II/5972) for analysis. A computercontrolled, air-actuated, multi-port solenoid valve system was used to achieve simultaneous injection of samples to the capillary ( $\mathrm{HP}-5$, $60 \mathrm{~m} \times 0.25 \mathrm{~mm} \times 0.25 \mu \mathrm{m})$ and packed columns ( $6 \mathrm{ft}$ Hayesep T and $30 \mathrm{ft}$ Hayesep DB, Alltech). The packed columns were connected to a thermal conductivity detector (TCD) for the analysis of low molecular weight species. The capillary column was used for higher molecular weight species and connected to a quadrupole mass spectrometer. The sampling system was maintained at about $300^{\circ} \mathrm{C}$ and at subambient pressures to minimize the condensation and/or adsorption of high molecular weight species on surfaces. Species quantifications were done either by direct calibration standards (Matheson Gas, Sigma Aldrich) or by the use of ionization cross section method [11]. The spe- cific methods used for various species have been reported earlier [12], thus, will not be repeated again here. We estimated an accuracy of $\pm 15 \%$ for the mole fractions of species determined by the direct calibration. The accuracy of the ionization cross-section method has been reported to be within a factor of two [12].

To reduce the thermocouple exposure time in sooting flames, the flame temperature was measured using a rapid insertion technique which include computer controlled motorized positioning, and a high speed data acquisition systems. A silicon oxide-coated $\mathrm{Pt}-13 \% \mathrm{Rh} / \mathrm{Pt}$, $0.075-\mathrm{mm}$ thermocouple with a bead diameter of about $0.15 \mathrm{~mm}$ (Omega Engineering Inc.) was attached to a motor driven assembly for linear positioning. A nuDrive Amplifier/Power Supply (National Instruments) was used to control the motor which was connected to a unislide assembly (Velmex Inc.). The motion control and data acquisition (5508Sci, American Data Acquisition Corporation) systems were synchronized by a personal computer in a program written in LabVIEW (National Instruments). After each measurement, thermocouple was withdrawn from the flame and the accumulated soot was burnt off using a small propane torch. The temperature profiles reported in this study correspond to direct thermocouple readings and were not corrected for radiation losses. We estimated an accuracy of about $\pm 50 \mathrm{~K}$ for temperature measurements.

Soot particle diameters, number densities, and volume fractions were determined using classical laser light scattering and extinction measurements (Fig. 1) [13]. The light source used was a tunable argon ion laser (Spectra Physics, 2037) with $514.5 \mathrm{~nm}$ line at a power of $1 \mathrm{~W}$. A photomultiplier tube (PMT) (Hamamatsu, $\mathrm{R} 1463)$ was used to measure the relative intensity of that fraction of the incident light scattered at $90^{\circ}$ by the soot particles in the flame being investigated. The transmitted light was measured with a photodiode (Hamamatsu, 51336-BQ) and recorded with an oscilloscope. To obtain high signal-to-noise ratio, it was necessary to reject light from all other sources, that is, flame luminosity and ambient light. Two devices were used to achieve this rejection: 1) Narrow band-pass filters were placed in front of the PMT and photodiode. 2) The incident laser 


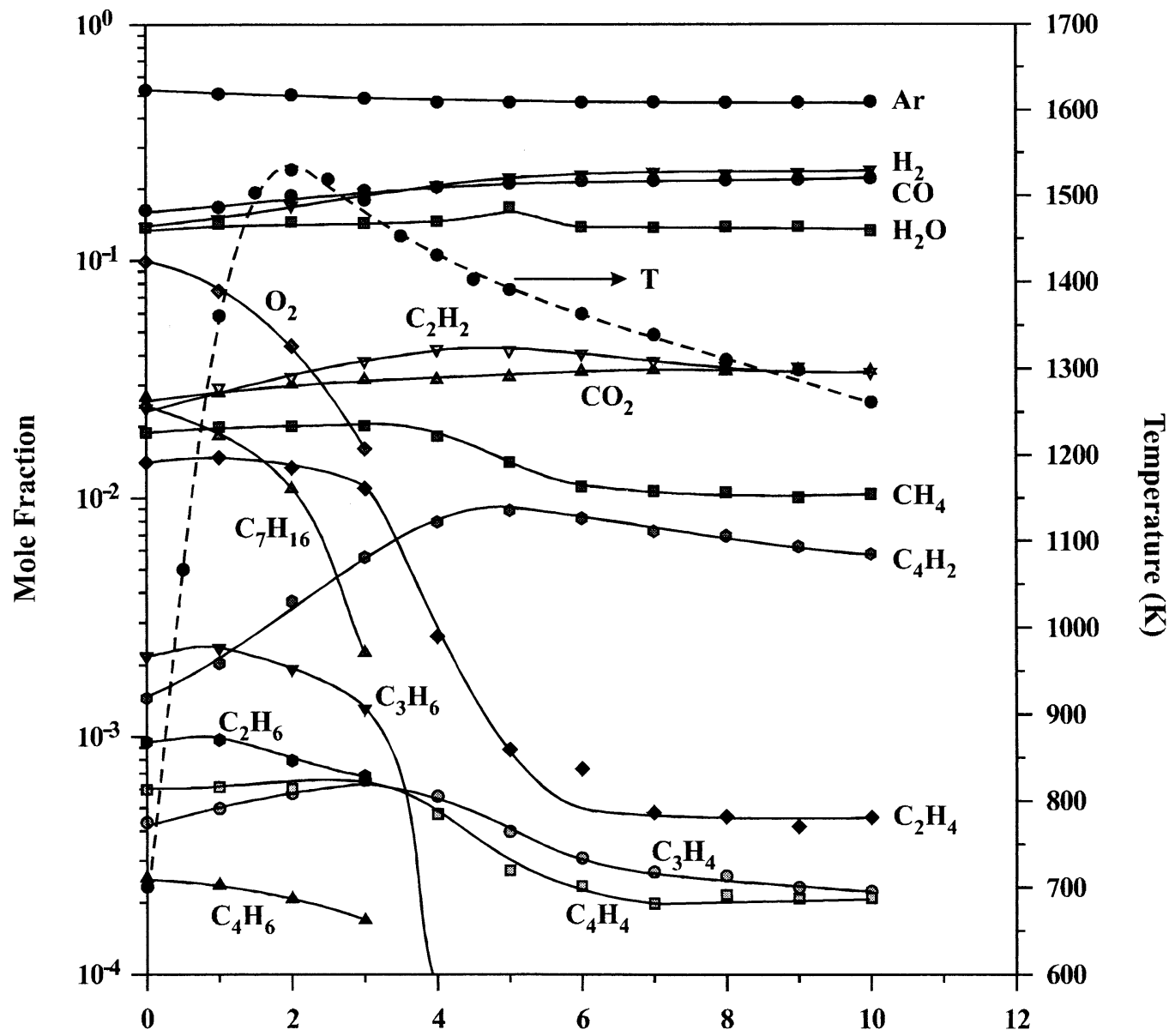

Height Above Burner Surface (mm)

Fig. 2. Major species mole fraction profiles and the temperature profile for Flame A.

light was chopped at a frequency of $1000 \mathrm{~Hz}$ and the PMT signal was read out with a lock-in amplifier (EG\&G 5205) which was synchronized with the chopper. Therefore, the lock-in amplifier read out only that component of the PMT output pulsed with the same frequency and phase as the chopper. The experimental set up was calibrated with a known particle-free flow composed of argon. Soot particle size, number density, and volume fraction calculations were carried out by assuming monodisperse particles having a complex refractive index of 1.54 to $0.58 \mathrm{i}[13,14]$.

Concentration, temperature, and soot profiles were obtained by moving the entire burner assembly vertically up or down. The positional accuracy associated with these measurements was estimated to be $\pm 0.2 \mathrm{~mm}$.

\section{RESULTS AND DISCUSSIONS}

The pre-combustion compositions of the flames studied are given in Table 1 . The equivalence ratio of 1.97 (Flame A) and 2.10 (Flame B) were determined to provide stable sooting flames that can be studied using our standard sampling microprobe [12]. Higher equivalence ratios resulted in excessive soot formation, which in return plugged the sampling probe orifice. At lower equivalence ratios, the flames did not produce as much $\mathrm{PAH}$ and soot. Before presenting experimental results, a number of issues related to the measurements should be discussed. First, the mole fraction data within a few millimeters above the burner surface should be considered questionable because of possible sampling probe-burner surface interactions. 


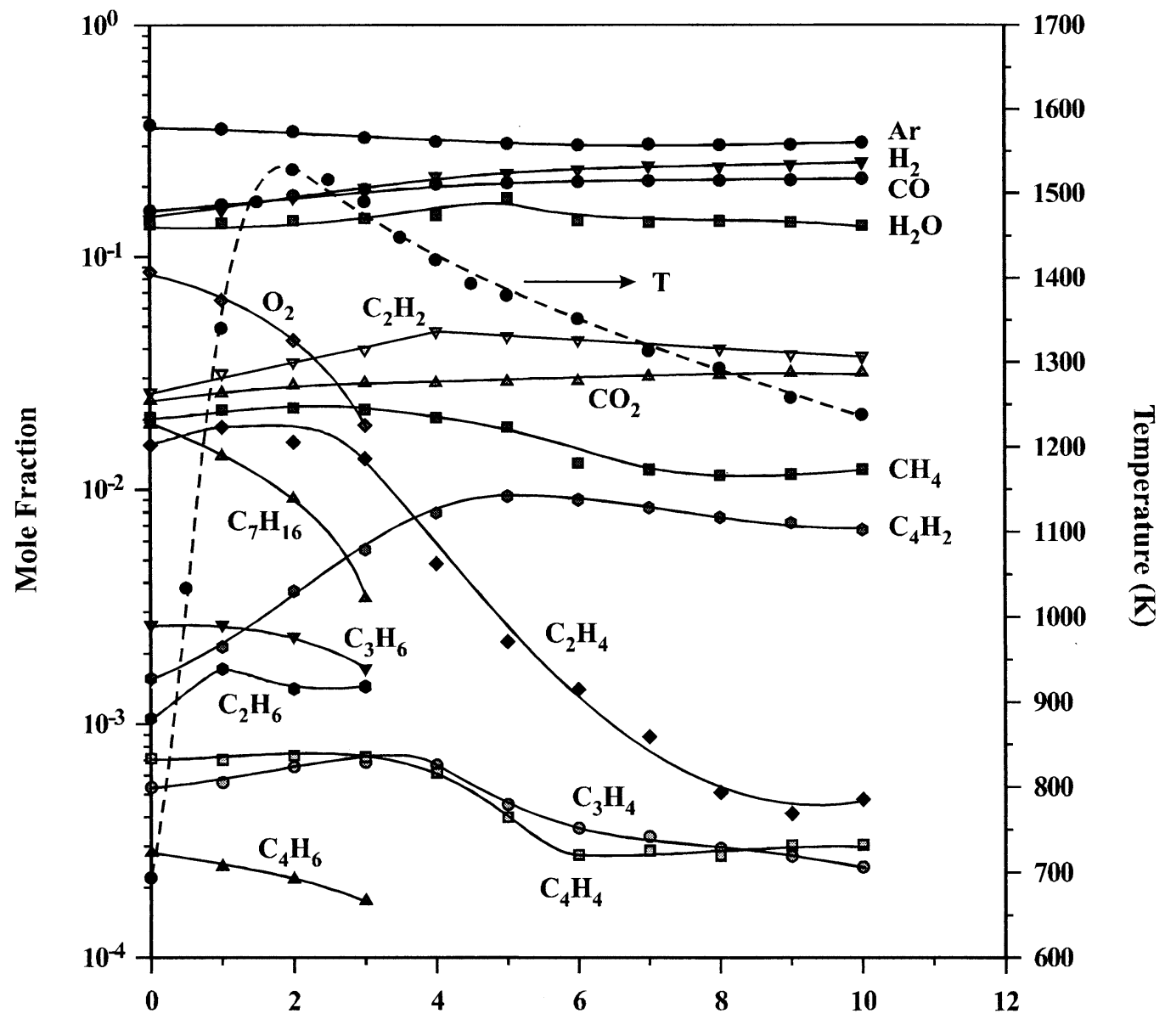

Height Above Burner Surface (mm)

Fig. 3. Major species mole fraction profiles and the temperature profile for Flame B.

Second, we used a sampling probe with an orifice diameter of about $0.200 \mathrm{~mm}$. Mole fraction profiles reported here represent values that are spatially averaged over 2 to 3 orifice diameters.

The major species mole fraction profiles are given in Fig. 2 and Fig. 3 for Flame A and Flame $\mathrm{B}$, respectively. Temperature profiles for these flames are also presented. The data points represent experimental results and solid lines represent trends in all the figures given in this study. As can be seen from Fig. 2, the temperature was about $700 \mathrm{~K}$ at burner surface and increased to a peak temperature of $1530 \mathrm{~K}$ at 2 $\mathrm{mm}$ above the burner surface. The difference in peak temperatures between Flame A and Flame $\mathrm{B}$ was about $5 \mathrm{~K}$, where the higher equivalence ratio flame showed lower temperature (Fig. 2 and Fig. 3). Because of their close equivalence ratios, both flames exhibited similar temperature profiles, within the accuracy of the measurements. Nevertheless, the results show a clear evidence that the temperature of the higher equivalence ratio flame (Flame B) was slightly cooler. However, the difference in two flame temperatures was higher in post flame region because of the soot formation. Although we used rapid insertion method for flame temperature measurements to reduce the thermocouple exposure time in sooting region, at higher distances above the burner surface, soot deposition on thermocouple bead was inevitable. This deposition process increased the radiative heat losses from the thermocouple bead and resulted in lower temperature readings. 


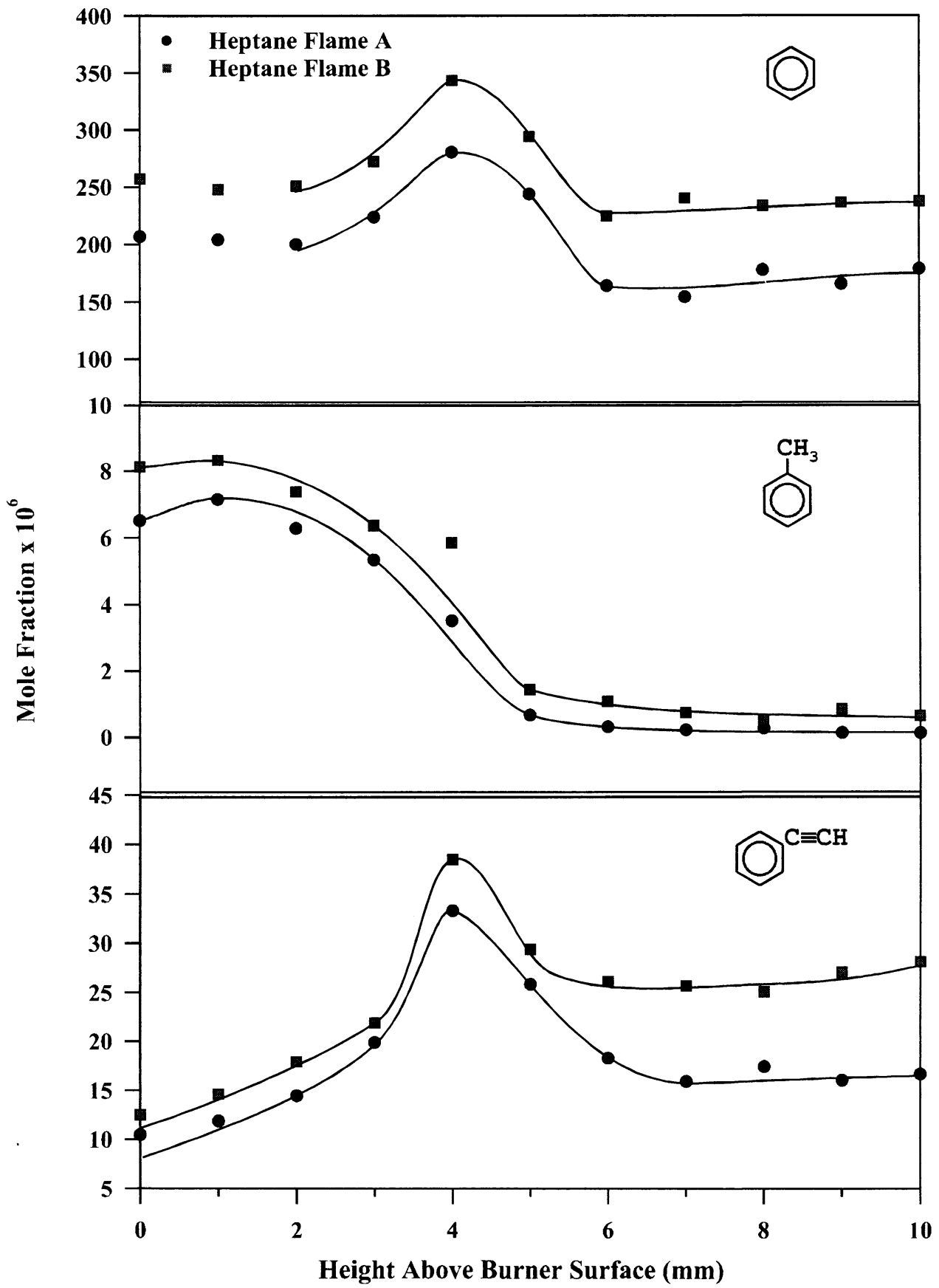

Fig. 4. Mole fraction profiles of benzene, toluene, and phenylacetylene.

Reactants $\mathrm{O}_{2}$ and $\mathrm{n}-\mathrm{C}_{7} \mathrm{H}_{16}$ were consumed within 3 to $4 \mathrm{~mm}$ above the burner surface. The most abundant species were $\mathrm{H}_{2}, \mathrm{CO}, \mathrm{H}_{2} \mathrm{O}$ in both flames as expected. Ar was used as diluent. $\mathrm{C}_{2} \mathrm{H}_{2}, \mathrm{CH}_{4}$ and the $\mathrm{C}_{4} \mathrm{H}_{2}$ were the primary hydrocarbon species detected with maximum mole fractions of $4.2 \times 10^{-2}, 2.0 \times 10^{-2}$, and $8.8 \times 10^{-3}$ for Flame $\mathrm{A}$ and $4.7 \times 10^{-2}, 2.2 \times$ $10^{-2}$, and $9.3 \times 10^{-3}$ for Flame B, respectively (Fig. 2 and Fig. 3). Their peak mole fractions were mostly in the post flame region except methane that showed broad profiles between 


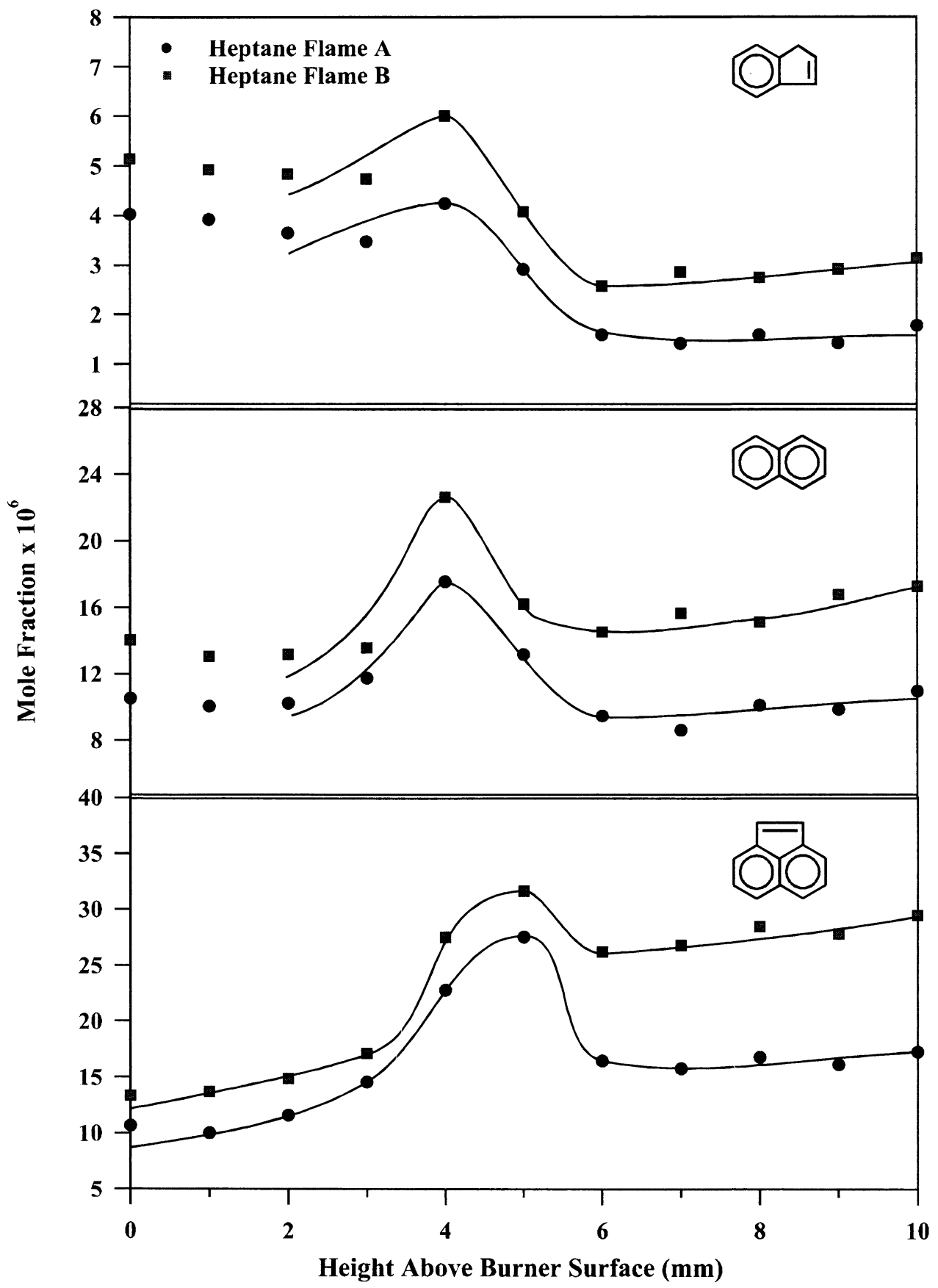

Fig. 5. Mole fraction profiles of indene, naphthalene, and acenaphthylene.

the 1.5 to $3 \mathrm{~mm}$. In contrast, the mole fraction profiles of $\mathrm{C}_{2} \mathrm{H}_{4}, \mathrm{C}_{2} \mathrm{H}_{6}$, and $\mathrm{C}_{3} \mathrm{H}_{6}$ peaked early in the flame region, indicating their role in the pre-flame reaction zone. Significant amounts of $\mathrm{C}_{3} \mathrm{H}_{4}$ and $\mathrm{C}_{4} \mathrm{H}_{4}$ were also detected in both flames studied.
At high temperatures, fuel consumption occurs by the thermal decomposition via C-C bond rupture and $\mathrm{H}$ atom abstraction by a number of radical species $[3,10,15-17]$.

$$
\mathrm{C}_{7} \mathrm{H}_{16}=\mathrm{n}-\mathrm{C}_{3} \mathrm{H}_{7}+\mathrm{p}-\mathrm{C}_{4} \mathrm{H}_{9}
$$




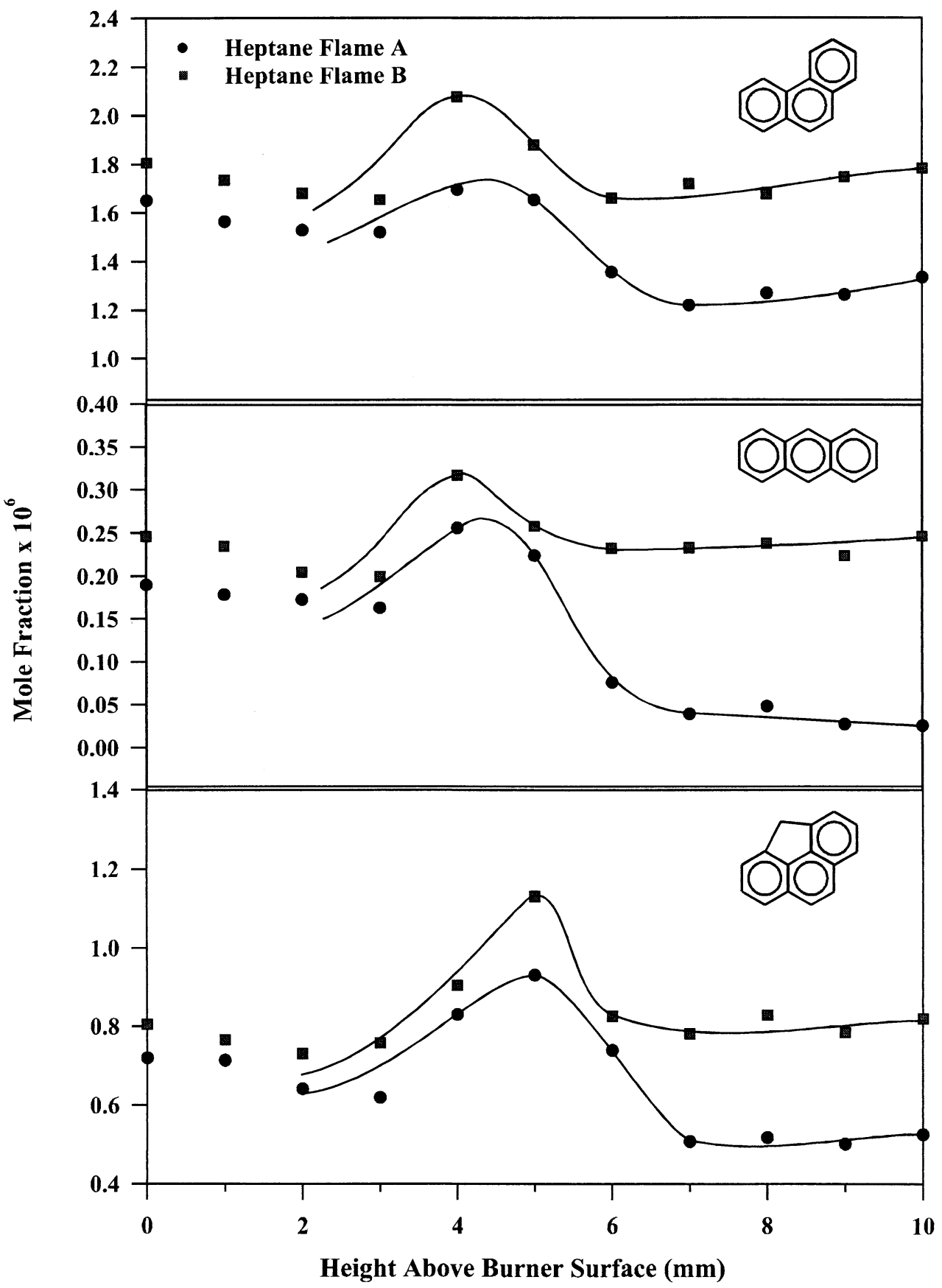

Fig. 6. Mole fraction profiles of phenanthrene, anthracene, and 4h-cyclopenta[def]phenanthrene.

$\mathrm{C}_{7} \mathrm{H}_{16}=1-\mathrm{C}_{5} \mathrm{H}_{11}+\mathrm{C}_{2} \mathrm{H}_{5}$

$\mathrm{C}_{7} \mathrm{H}_{16}=1-\mathrm{C}_{6} \mathrm{H}_{13}+\mathrm{CH}_{3}$

$\mathrm{C}_{7} \mathrm{H}_{16}+\mathrm{X} \rightarrow \mathrm{C}_{7} \mathrm{H}_{15}$

$+\mathrm{XH}\left(\mathrm{X}=\mathrm{H} / \mathrm{O} / \mathrm{OH} / \mathrm{HO}_{2} / \mathrm{CH}_{3}\right)$
The modeling studies for premixed n-heptane flames indicated that the dominant fuel consumption paths vary as a function of equivalence ratio. It has been suggested that the thermal decomposition path becomes increasingly important at higher equivalence ratios [17]. 


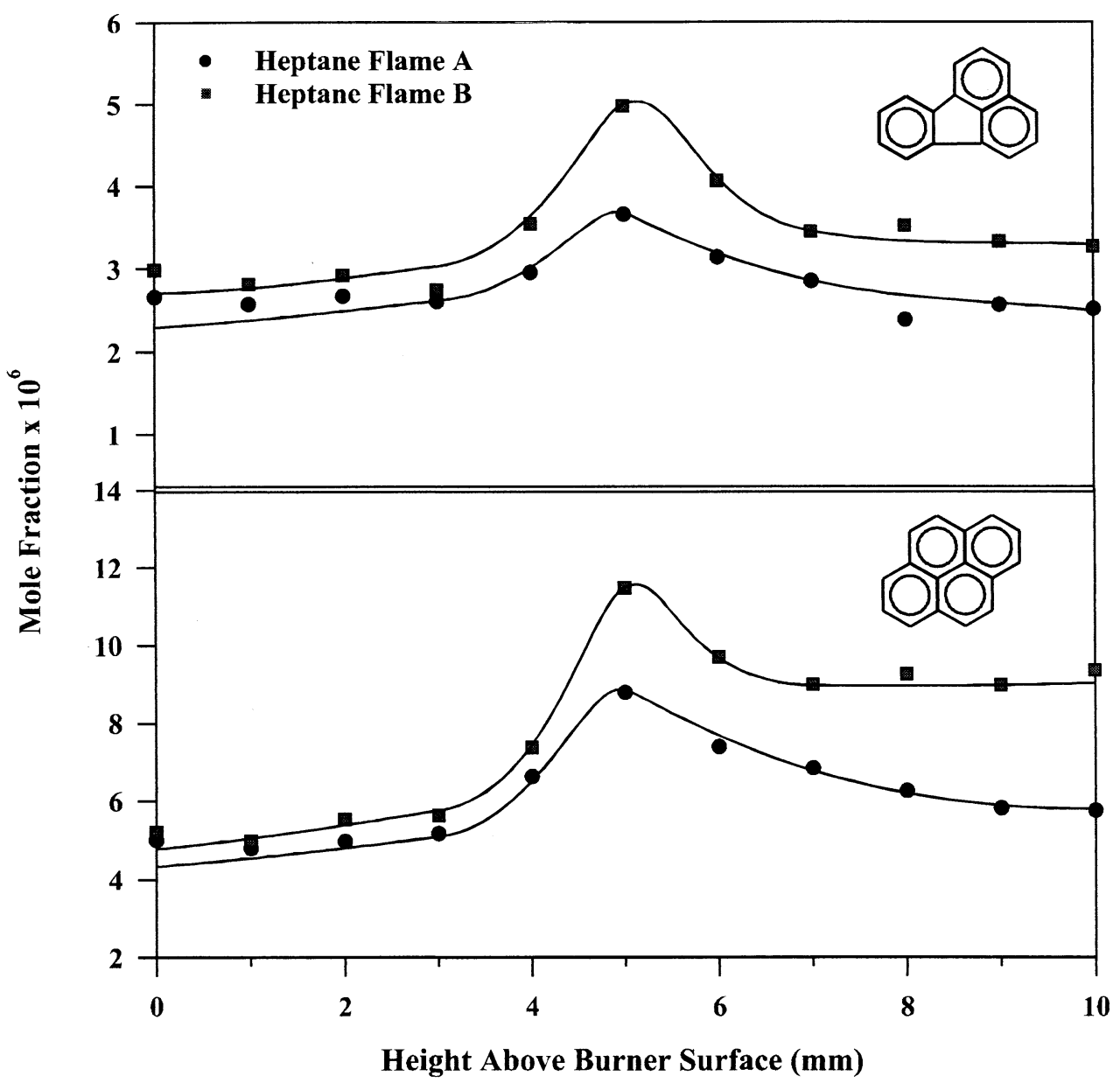

Fig. 7. Mole fraction profiles of fluoranthene and pyrene.

The four isomers of $n$-heptyl radical $\left(\mathrm{C}_{7} \mathrm{H}_{15}\right)$ which are formed by the $\mathrm{H}$-atom abstraction reactions primarily consumed through the $\beta$-scission of a C-C bond at high temperatures [3,15,17-19].

$1-\mathrm{C}_{7} \mathrm{H}_{15}=\mathrm{C}_{2} \mathrm{H}_{4}+1-\mathrm{C}_{5} \mathrm{H}_{11}$

2- $\mathrm{C}_{7} \mathrm{H}_{15}=\mathrm{C}_{3} \mathrm{H}_{6}+\mathrm{p}-\mathrm{C}_{4} \mathrm{H}_{9}$

$3-\mathrm{C}_{7} \mathrm{H}_{15}=1-\mathrm{C}_{4} \mathrm{H}_{8}+\mathrm{n}-\mathrm{C}_{3} \mathrm{H}_{7}$

$3-\mathrm{C}_{7} \mathrm{H}_{15}=1-\mathrm{C}_{6} \mathrm{H}_{12}+\mathrm{CH}_{3}$

4- $\mathrm{C}_{7} \mathrm{H}_{15}=1-\mathrm{C}_{5} \mathrm{H}_{10}+\mathrm{C}_{2} \mathrm{H}_{5}$

In addition to thermal decomposition, isomerization reactions of these four n-heptyl radicals are also important.
For comparison reasons, aromatic and $\mathrm{PAH}$ compound mole fraction profiles at two different equivalence ratios are given in the same figure for each compound (Fig. 4-Fig. 8). Figure 4 shows the concentration profiles for benzene, toluene, and phenylacetylene. Benzene was the major aromatic species in both flames reaching maximum mole fractions of $280 \mathrm{ppm}$ and 343 ppm for Flame A and Flame B, respectively. These levels are similar to the benzene levels reported by Bakali et al. [20] in their 1.9 equivalence ratio n-heptane flame. As expected, increase in equivalence ratio increased the mole fractions of aromatic and PAH species. Most of them peaked at or above the $4 \mathrm{~mm}$ from the burner surface. Toluene was the exception, 


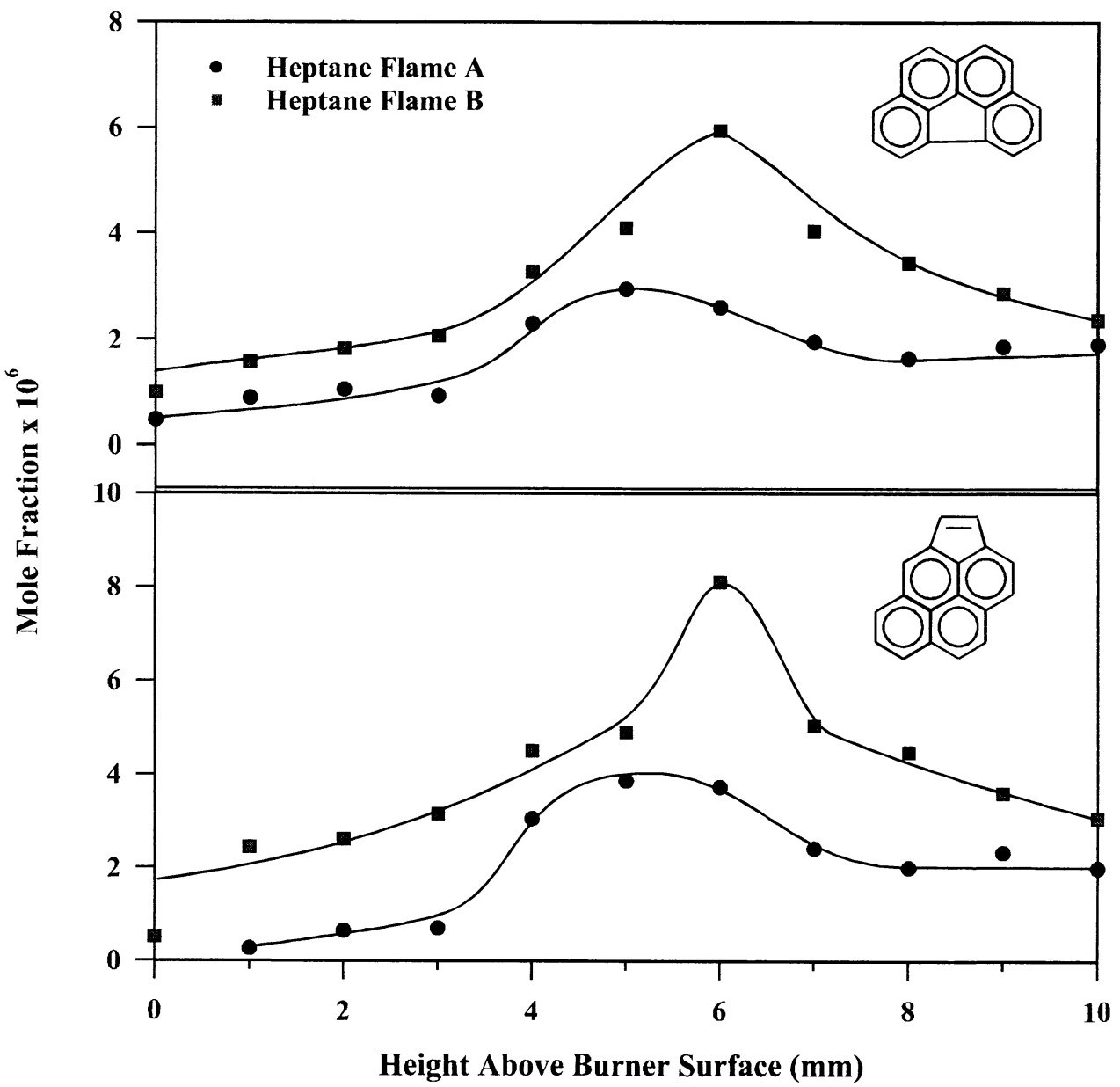

Fig. 8. Mole fraction profiles of benzo[ghi]fluoranthene and cyclopenta[cd]pyrene.

which showed a maximum around $1 \mathrm{~mm}$. A similar trend for toluene was also reported for the premixed combustion of other hydrocarbon fuels [21].

Frenklach and Wang [22] proposed that the formation of first aromatic ring in flames of non-aromatic fuels begins with vinyl addition to acetylene. Vinylacetylene is formed at high temperatures, and followed by acetylene addition to $\mathrm{n}-\mathrm{C}_{4} \mathrm{H}_{3}$ radical formed by the $\mathrm{H}$-abstraction from the vinylacetylene. The benzene can also be formed by combination of propargyl radicals producing benzene or phenyl [23]. The modeling studies for n-heptane diffusion flames have showed that the benzene formation occurs through both the $\mathrm{C}_{3}$ and $\mathrm{C}_{4}$ chains [15]. The larger aromatics can be built by the addition of non-aromatics such as $\mathrm{C}_{2} \mathrm{H}_{2}$ and $\mathrm{C}_{4} \mathrm{H}_{5}$. The addition of aromatic radicals to non-aromatics can also lead to condensed ring compounds [24].

As presented in Fig. 5, acenaphthylene was the most abundant $\mathrm{PAH}$ in both Flame $\mathrm{A}$ and Flame B with peak mole fractions of about 27 ppm and $32 \mathrm{ppm}$ respectively. Other researchers have also reported acenaphthylene as a major PAH species in premixed and diffusion flames of n-heptane [5, 9].

The concentrations of phenanthrene (MW 178), pyrene (MW 202), and cyclopenta[cd]pyrene (MW 226) were higher than their isomers anthracene, fluoranthene, and benzo[ghi]fluoranthene in both flames (Fig. 6-Fig. 8). However, the difference in isomer concentra- 


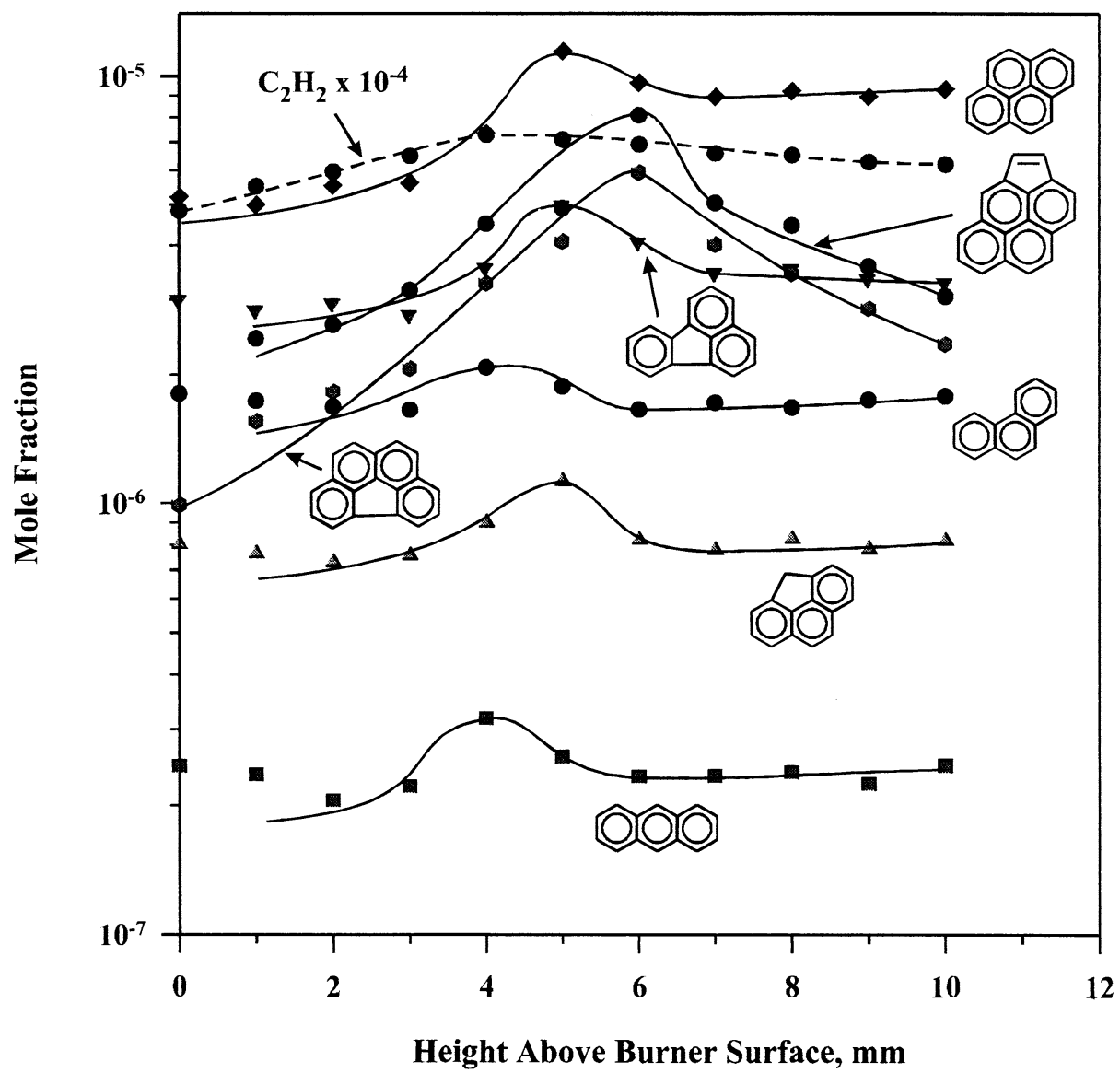

Fig. 9. Mole fraction profiles of acetylene and 3- and 4-ring aromatic compounds in Flame B.

tion was significantly lower for molecular weight of 226 species. The largest $\mathrm{PAH}$ detected were the molecular weight of $226\left(\mathrm{C}_{18} \mathrm{H}_{10}\right)$ species including cyclopenta[cd]pyrene and benzo[ghi]fluoranthene (Fig. 8). Their mole fractions were about $3 \mathrm{ppm}$ and $2.5 \mathrm{ppm}$ in Flame $\mathrm{A}$ and 8 ppm and 6 ppm in Flame B, respectively.

Because the hydrogen abstraction-acetylene addition (HACA) is one of the proposed PAH growth mechanism [25], the mole fraction profiles of acetylene and 3- and 4-ring $\mathrm{PAH}$ (Phenanthrene, anthracene, 4 h-cyclopenta[def]phenanthrene, fluoranthene, pyrene, benzo[ghi]fluoranthene, cyclopenta[cd]pyrene) are presented in Fig. 9 for Flame B as representative data. It is important to note that most of the PAH species peaked at a point where acetylene mole fraction had already started to decrease.
Soot properties were calculated by assuming spherical monodisperse soot particles to comply with the Rayleigh scattering approximation. Although non-spherical and polydisperse soot occurs within the flame because of the agglomeration of primary soot particles, the Rayleigh approximation has been shown to hold to within a factor of three [26]. Soot particle diameters, number densities, and volume fractions are presented for n-heptane flames at two different equivalence ratios in Fig. 10. The maximum soot particle diameter was about $18 \mathrm{~nm}$ and the soot volume fraction reached the amount of $4.9 \times 10^{-7}$ in Flame B. As can be seen from this figure, the soot volume fraction or amount of soot was initially only small fraction of the final amount. As soot volume fraction increases, the particles also grow in size. At the same time, 


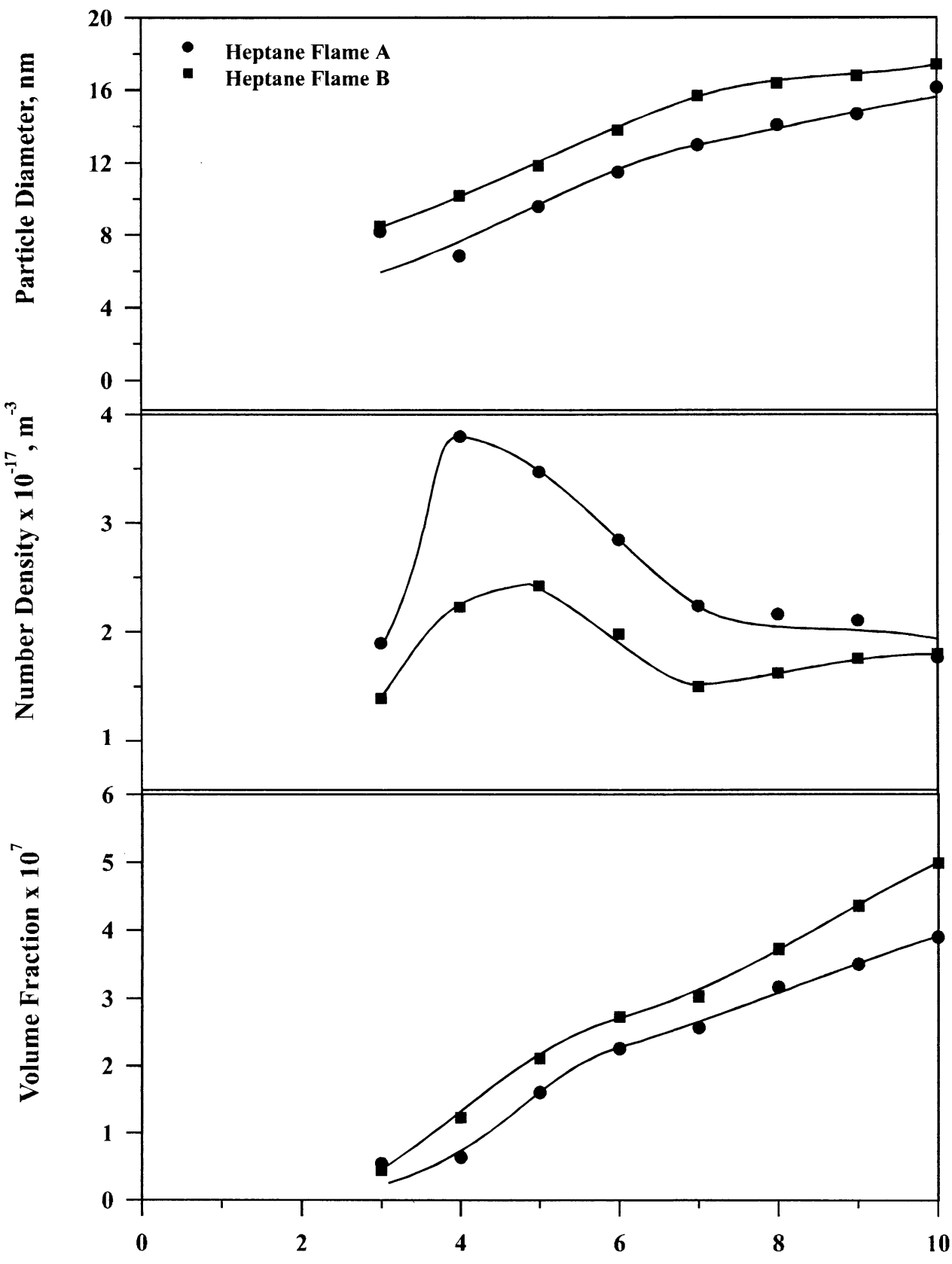

Height Above Burner Surface, mm

Fig. 10. Effects of equivalence ratio on soot formation.

their number densities decrease. The decrease in soot number densities can be because of the coagulation of soot particles. The temperature affects the rate of formation of soot precursors through fuel pyrolysis and the rate of oxidative
$(\mathrm{OH})$ attack on these precursors in premixed sooting flames [27]. Both rates increase with temperature. However, the oxidative attack rate increases faster. Therefore, the higher temperature flame (Flame A) produced less soot. 


\section{CONCLUSIONS}

For the first time, we have determined the microstructure of atmospheric-pressure, premixed, laminar flat flames of n-heptane/oxygen/ argon at two fuel-rich equivalence ratios. The experimental data on soot particle measurements are also reported in this study. Stable major, minor, and trace species mole fraction profiles were obtained by direct analysis of flame samples. Increase in equivalence ratio, increased the concentration of aromatic and PAH species, as expected. Benzene was the major aromatic species. Acenaphthylene and naphthalene were the most abundant $\mathrm{PAH}$ compounds detected. Our results for species mole fraction profiles were in agreement with those reported earlier in the literature. Flame $\mathrm{B}$, the richer flame, produced more soot and larger particles than Flame A. The measurements reported in this study can be used to develop and verify detailed chemical kinetic mechanisms describing the formation of $\mathrm{PAH}$ and soot in the combustion of n-heptane.

\section{REFERENCES}

1. Burcat, A., Int. Symp. on Shock Tubes and Waves 13:826-833 (1981).

2. Ciezki, H., and Adomeit, G., Int. Symp. on Shock Tubes and Waves 16:481-486 (1987).

3. Chakir, A., Bellimam, M., Boettner, J. C., and Cathonnet, M., Int. J. Chem. Kinetics 24:385-410 (1992).

4. Dagaut, P., Reuillon, M., and Cathonnet, M., Combust. Flame 101:132-140 (1995).

5. Westmoreland, P. R., Howard, J. B., and Longwell, J. P., Second Ann. Progress Report-Center for Health Effects of Fossil Fuel Utilization MIT:1980.
6. Doute, C., Delfau, J. L., Akrich, R, and Vovelle, C., Combust. Sci. Tech. 124:249-276 (1997).

7. Ingemarsson, A. T., Pedersen, J. R., and Olsson, J. O., J. Phys. Chem. A 103:8222-8230 (1999).

8. Hamins, A., and Seshadri, K., Combust. Flame 68:295307 (1987).

9. Peterca, L., and Marconi, F., Combust. Flame 78:308325 (1989).

10. Coats, C. M., and Williams, A., Proc. Combust. Inst. 17:611-621 (1979).

11. Fitch, W. L., and Sauter, A. D., Anal. Chem. 55:832835 (1983).

12. Castaldi, M. J., Vincitore, A. M., and Senkan, S. M., Combust. Sci. Tech. 107:1-19 (1995).

13. Flower, W. L., SPIE 644:28-39 (1986).

14. Faeth, G. M., and Koylu, U. O., Combust. Sci. Tech. 108:207-229 (1995).

15. Lindstedt, R. P., and Maurice, L. Q., Combust. Sci. Tech. 107:317-353 (1995).

16. Warnatz, J., Proc Combust. Inst. 20:845-856 (1984).

17. Held, T. J., Marchese, A. J., and Dryer, F. L., Combust. Sci. Tech. 123:107-146 (1997).

18. Westbrook, C. K., Warnatz, J., and Pitz, W. J., Proc. Combust. Inst. 22:893-901 (1988).

19. Dagaut, P., Reuillon, M., and Cathonnet, M., Combust. Sci. Tech. 95:233-260 (1994).

20. Bakali, A. E., Delfau, J-L., Vovelle, C., Combust. Sci. Tech. 140:69 (1998).

21. Melton, T., Inal, F., and Senkan, S. M., Combust. Flame 121:671-678 (2000).

22. Frenklach, M., and Wang, H., in Soot Formation in Combustion (Bockhorn, H., Ed.) Springer-Verlag, Berlin, p. 165, 1994.

23. Miller, J. A., and Melius, C. F., Combust. Flame 91:21-39 (1992).

24. Bittner, J. D., and Howard, J. B., Proc. Combust. Inst. 18:1105-1116 (1981).

25. Kazakov, A., Wang, H., and Frenklach, M., Combust. Flame 100:111-120 (1995).

26. Koylu, U. O., Combust. Flame 109:488-500 (1996).

27. Glassman, I., Proc. Combust. Inst. 22:295-311 (1988).

Received 4 December 2001; revised 12 April 2002; accepted 22 April 2002 